Review Article

\title{
An overview of breast cancer: Classification and related signaling pathways
}

\author{
Pit Foong Chan*, Roslida Abd Hamid
}

\begin{abstract}
Article History
Department of Biomedical Science, Faculty of Medicine and Health Sciences,

Received: 21 January 2021;

Universiti Putra Malaysia, 43400 Serdang, Selangor, Malaysia; roslida@upm.edu.my (RAH)

Received in Revised Form: *Corresponding author: Pit Foong Chan, pitfoong_chan@hotmail.com (P-FC) 31 March 2021;
\end{abstract}

Accepted: 1 April 2021;

Available Online: 12 April 2021

\begin{abstract}
The burden of cancer continues to grow in developed and developing countries, with about $70 \%$ of all cancer mortality in low- and middle-income countries. Among different cancer types, breast cancer is recognized as one of the five most common causes of death in cancer in women worldwide, right after lung cancer. Histological classification divides breast tumors into different categories based on their behavior and clinical outcome. However, the histological classification system has some limitations, thus molecular subtype classification has been studied extensively to improve the classification system for breast cancer. Like any other cancers, several signaling pathways that enhance the proliferation, survival, invasion, and metastasis capability of tumor cells have been observed in breast cancer. These crucial signaling pathways contributing to the etiology of breast cancer include breast tumor kinase (BRK) pathway, Notch signaling, Nuclear Factor-kappaB (NF- $\kappa \mathrm{B})$ pathway, and human epidermal growth factor receptor (HER) pathway. In the present review article, we summarize our current understanding of breast cancer and its signaling pathways, which serve as basic information on tumor formation, maintenance, and expansion that could help form better breast cancer management in patients.
\end{abstract}

Keywords: breast cancer, signaling pathway, BRK, NF- $\mathrm{B}, \mathrm{HER}$

\section{Introduction}

Cancer has become one of the top causes of morbidity and mortality, with approximately 18.1 million new cases and about 9.6 million deaths in 2018 based on the Global Cancer Observatory $^{[1]}$. In other words, cancer is responsible for nearly one of the six deaths, leading to its recognition as one of the world's most prominent "killers" ${ }^{[1,2]}$. In addition to that, it has been suggested that nearly $65 \%$ of the increase in deaths related to all cancer types will occur in less developed regions of the world by the year 2030 while developing countries are anticipated to face an estimated burden of 23.6 million new cases per year ${ }^{[3-6]}$. 
As the leading malignancy in females, breast cancer cases continue to increase over the past few years, with a distinctive age-specific pattern reported by Bray and the team ${ }^{[1,7]}$ By the same token, the disease may have an early onset age, occurring in younger women below 40 years of age and statistics showed a sharp increase in incidence rate right before menopause ${ }^{[1,8]}$. A recent report by Sharma, which extracted information from the GLOBOCAN 2018, stated that breast cancer had claimed an estimation of 626679 lives at an age-standardized rate of $13 / 100000^{[9]}$. In the same report, the highest incidence of breast cancer was noted in East Asia with 476509 cases (range: $474656-478370$ cases), but the highest death counts due to breast cancer were observed South-central Asia at 123,060 deaths (range:119,256-126,986) in 2018. In Malaysia, the Health Facts $2013^{[10]}$ released by the Ministry of Health $(\mathrm{MoH})$ Malaysia highlighted cancer as one of the top ten causes of hospitalization and one of the top five causes of mortality (approximately 30000 cases annually). Based on the report released by the Malaysian National Cancer Registry Report (2016) ${ }^{[11]}, 103507$ new cancer cases were diagnosed between 2007 and 2011 in Malaysia, and breast cancer appeared to be the most common cancer among female residents $(32.1 \%)$ in Malaysia.

Along with the advancement of detection technology, the survival rate of breast cancer patient seems to have improved through surgery, radiotherapy, chemotherapy, endocrine therapy, and targeted therapy ${ }^{[12]}$. While chemotherapy remained the broadest approach and first choice applied in inhibiting cancer cells' proliferation, it is often militated by numerous factors comprised of chemo-resistance, non-selectivity actions of chemotherapeutic agents, and high proliferation rates in breast cancer cells ${ }^{[13]}$. In fact, these prominent characteristics of cancer cells are often the result of abnormal activation of signaling pathways that granted these cells increased proliferation ability, along with invasion and metastasis capability. Therefore, a better understanding of underlying signaling pathways is essential, particularly in ensuring an excellent therapeutic plan and achieving the best clinical outcome.

\section{Histological Classification of Breast Cancer Subtypes}

The breast is comprised of two main types of tissue: (a) glandular tissues that house lobules (i.e., milk-producing glands) and ducts, and (b) stromal tissues, which provide the "supporting framework" of the breast (i.e., fatty and connective tissues) (Figure 1) $)^{[14]}$. However, due to the lack of biomarkers, the definition of breast cancer advancement remains challenging compared to other cancer types like colon cancer ${ }^{[15,16]}$. Through histological investigations, breast cancer can be differentiated based on its site and invasiveness. The invasive form of breast cancer is seen to breach the duct and lobular wall, invading the breast's supporting tissues. Despite that, this does not imply its metastatic capability, as some breast cancer can be invasive but do not spread further to other organs or lymph nodes. The other form of breast cancer is carcinoma in situ or non-invasive breast cancer, which can be subcategorized into two types: either ductal carcinoma in situ (DCIS) or lobular carcinoma in situ (LCIS). Generally, DCIS is considered as pre-invasive or non-invasive breast cancer and constitutes one in five new breast cancer cases reported. However, untreated DCIS may spread 
over time by invading into adjacent breast tissue and progress into invasive cancer. The detection of DCIS has increased significantly following the use of mammography screening. In the United States, $90 \%$ of DCIS cases detected through mammography are observed as suspicious calcifications. DCIS is further categorized into several subtypes, primarily based on the morphological appearances: Comedo, Cribiform, Micropapillary, Papillary and Solid ${ }^{[17]}$. On the contrary, LCSI is rather a rare condition in which abnormal cells develop in the lobules at the terminal end of the duct. It is also displaying a worrying trend, given that the number of LCSI cases has multiplied over the past few years, with the highest rate observed among women aged between 40 to 50 years ${ }^{[18]}$.

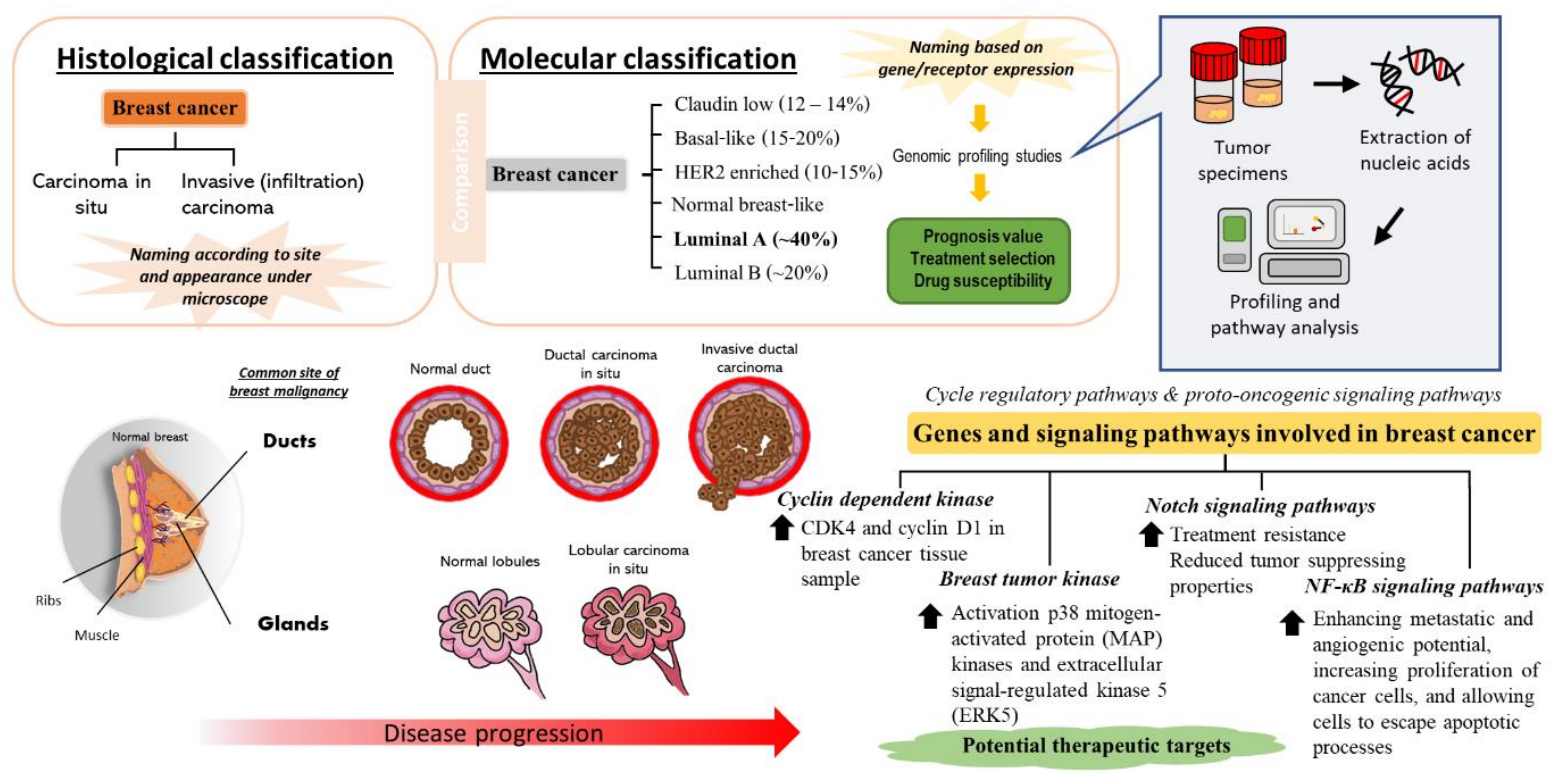

Figure 1. Classification of breast cancer subtypes and examples of signaling pathways involved in the etiology of breast cancer ${ }^{[19,20]}$.

On the other hand, the major invasive tumor types are infiltrating ductal, invasive lobular, ductal/lobular, mucinous (colloid), tubular, medullary, and papillary carcinomas. Being the most prevalent type of invasive breast cancer, infiltrating ductal carcinoma (IDC) accounts for approximately $80 \%$ of all invasive breast cancers. As indicated by its naming, IDC arises in the breast's ductal region, invading through the duct wall, and subsequently expands into the supporting tissue of the breast. There are three grades of IDC: well-differentiated (grade 1), moderately differentiated (grade 2), or poorly differentiated (grade 3 ). The grading of IDC is carried on based on the rate of nuclear pleomorphism, glandular/tubule formation, and mitotic index, which aids in its prognosis ${ }^{[21]}$.

\section{Molecular Classification of Breast Cancer Subtypes}

Originally assumed as a single disease, more evidence is emerging on breast cancer's complexity, suggesting it to be a group of diseases expressing distinguishable anatomical characteristics, reactive towards treatment and survival result. Current histological classifications greatly limit the ability to completely identify the clinical results of this 
disease $^{[22]}$. With the availability of more affordable molecular techniques, including genome sequencing technologies, researchers are now getting more insights into breast cancer subtyping via gene expression and genomic profiling studies. While the current model for breast cancer classification may offer some levels of prognostic value, the molecular classification of breast cancer offers more tremendous advantages in predicting the clinical outcome and, more importantly, assessing potential (distinctive) responses to specific therapies that assist clinicians in choosing the best therapeutic options for breast cancer patients ${ }^{[23,24]}$.

Perou and team studied the gene expression of different breast cancer types using cDNA microarray profiling and sorted them into few intrinsic gene subtypes: basal-like breast cancer (BLBC) (estrogen receptor (ER) negative, progesterone-receptor (PR) negative, and human epidermal growth factor receptor-2 (HER2) negative), HER2-enriched, normal breast-like, luminal subtype A (ER+ and low grade) and luminal subtype B (ER+ and often high grade $)^{[25-}$

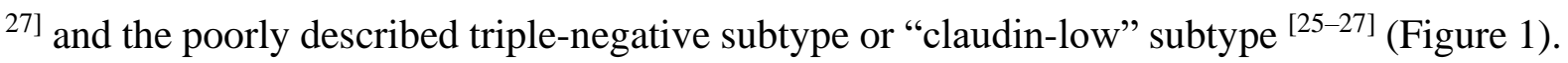
Each of these molecular subgroups has a distinctive prognosis and chemotherapy sensitivity.

Additionally, the growth of breast cancer cells can be induced by hormones, estrogen, and progesterone. Thus, selecting specific therapy for breast cancer varies depending on these hormone receptors' expression ${ }^{[28,29]}$. Generally, $70 \%$ of breast cancer patients express ER and receive hormonal therapy treatment ${ }^{[28,30,31]}$. Studies also indicated that those with luminal-like cancers seem to have better long-term survival compared with other cancers, but those with basal-like and HER-2-positive tumors show higher susceptibility and sensitivity towards chemotherapy ${ }^{[26,32]}$. In contrast, patients diagnosed with triple-negative cancer have exceptionally shorter survival in first metastatic occurrence than other breast cancer types ${ }^{[33]}$.

By molecular classification, ER-positive luminal breast cancer is the most common type of invasive breast cancer. The ER-positive disease can be further classified into subtypes with different outcomes (i.e., luminal A and luminal B) using gene expression profiling with microarrays ${ }^{[34]}$. Luminal A tumors tend to have high expression of ER-activated genes, lowgrade histological appearance, and slower growth, resulting in a better prognosis than luminal B tumors ${ }^{[35]}$. Furthermore, luminal A tumors are associated with the expression of luminal epithelial cytokeratins (CK) 8 and 18, other genes such as hepatocyte nuclear factor 3 alpha (FOXA1), B cell lymphoma 2 (BCL2), erbB3, and erbB $4^{[36]}$. In comparison, luminal B tumors typically display a high proliferate rate and tumor aggressiveness, which is subsequently explained by its high relapse rate and lower survival rates than luminal-A breast cancer ${ }^{[37-40]}$. The main difference between these two luminal subtypes is the greater level of proliferationrelated genes expressions such as avian myeloblastosis viral oncogene homolog ( $v-M Y B)$, gamma glutamyl hydrolase (GGH), lysosome-associated transmembrane protein 4-beta (LAPTMB4), nuclease sensitive element binding protein 1 (NSEP1) and cyclin E1 $(C C N E 1)$ in luminal-B tumors ${ }^{[41]}$. It should be noted that luminal tumors form a continuum, thus the determination of these tumors into two subtypes based on proliferation may be $\operatorname{arbitrary}^{[42]}$. 
The HER2 is overexpressed in 15-30\% of invasive breast cancer, mainly due to the overexpression of HER2/HER2 signaling-related genes and genes located in the HER2 amplicon on chromosome $17 q 12^{[25]}$. Even though HER2-enriched breast cancer can proliferate faster than luminal cancers, they are often highly responsive to targeted therapies aimed at the HER2 protein, resulting in remarkably improved outcomes ${ }^{[43]}$. The normal cell-like subgroup, comprising $5-10 \%$ of breast cancer patients ${ }^{[44]}$. Some researchers defined that this subtype was featured by similar gene expression to normal breast epithelium. Its proliferation rate is often low and responds to adjuvant chemotherapy ${ }^{[44,45]}$.

The BLBC is an aggressive subtype that mainly occurs in young women and displays exceptionally high metastasis rates to the brain and lung ${ }^{[46,47]}$. This subtype is characterized by high histological grade, poor tubule formation, central necrotic zones, pushing borders, high mitotic indices, and proliferation rates ${ }^{[47]}$. Furthermore, the BLCL does not benefit from antiestrogen hormonal treatment or trastuzumab as estrogen receptor (ER), progesterone receptor (PR), and HER2 were not expressed in this subtype. Therefore, a better understanding of the molecular background of BLBC to develop promising therapeutic regimes is necessary ${ }^{[48]}$. For instance, a study conducted by Hallett et al.$^{[49]}$ distinguished BLBC into two subgroups based on 14-gene. They assumed that this categorization might provide aggressive therapeutic regimes to the poor prognosis subgroup while avoiding such treatment in low-risk patients ${ }^{[50]}$.

\section{Genetic and Hormonal Risk Factors in Breast Cancer}

In general, cell DNA impairment can cause mutations or chromosome rearrangements, which leads to carcinogenesis. Undoubtedly, breast cancer is a complex and multifactorial disease due to hormonal or genetic factors, or even a combination of both factors, as seen in many cases. Hormonal factors, main estrogen, play a vital role in breast cancer development ${ }^{[51]}$. Researchers hypothesized that excessive production of estrogen could stimulate the aberrant growth and development of organs affected by hormonal levels ${ }^{[52]}$. By this theory, hyperplasia tissue may pose as a "preview" before neoplasia development. However, while this is true, breast cancer risk appears to be predictable by the exposure to estrogen ${ }^{[53]}$.

BRCA1 (Breast Cancer gene one) and BRCA2 (Breast Cancer gene two) are two of the most important breast cancer susceptibility genes ${ }^{[54]}$. The $B R C A$ genes play a critical role in cell damage repair and induce cell death to those cells if the damage is beyond rescue ${ }^{[55]}$. BRCA mutation leads to abnormal breast tissue proliferation and increases breast cancer risk ${ }^{[55,56]}$. It has been estimated that 5-10\% of breast cancers diagnosed in women are associated with hereditary susceptibility, attributed to mutations in autosomal dominant genes, such as BRCAl and $B R C A 2^{[20,57]}$. Aside from that, $15-20 \%$ of female breast cancers occurred due to family inheritance but without a plausible autosomal dominant genes type ${ }^{[58]}$. There have been more than 500 sequence variations were identified since the isolation of $B R C A 1$. Despite most are frameshift mutations, several missense mutations are reported that may alter the specific function of a protein. Furthermore, splice donor or acceptor site mutations are commonly reported $^{[59]}$. The mutation spectrum of $B C R A 2$ may not as established as that of BRCA1. 
However, the mutations reported in BRCA2 mainly happen in exons 10 and 11 and always include insertions or deletions; these unwanted changes then cause missense alterations and premature stop codon seen in truncated and completely nonfunctional protein ${ }^{[60]}$.

\section{Signaling Pathways Involved in Breast Cancer}

Knowing the exact mechanisms involved in any disease, including breast cancer, is essential before deciding on appropriate treatments. Lately, newer approaches are designed to target cell cycle regulatory pathways, proto-oncogenic signaling pathways targeted agents such as Notch, Wnt, SHH (Sonic hedgehog), ER (estrogen receptor), PI3k/AKT/MTOR, and HER2 (human epidermal growth receptor 2) ${ }^{[61]}$. Besides that, researchers also investigate the potential of focusing on the breast tumor microenvironment as a therapeutic target in breast cancer ${ }^{[62]}$.

\subsection{Cyclin Dependent Kinase}

There are three main key families of molecules involved in cell cycle regulation, namely cyclins, cyclin dependent kinase (CDKs), and cyclin dependent kinase inhibitors (CDKIs) ${ }^{[63]}$. Dysregulation of the interplay between cyclins and their related CDK partners contributes to one of the hallmark features of cancer, a sustained proliferation of tumor cells ${ }^{[64]}$. CDKs could be either overactive or CDK-inhibiting proteins that are not in function in most cancers ${ }^{[61]}$. A study suggests that remarkable overexpression of CDK4 and cyclin D1 occurred in breast tumors. Consequently, it has been postulated that CDK4 is dispensable for the development of the normal mammary gland and poses as a suitable therapeutic target, specifically promote breast cancer cells inhibition while sparing other healthy cells ${ }^{[65,66]}$,

\subsection{Breast Tumor Kinase}

The overexpression of breast tumor kinase (BRK) has been implicated in several malignancies such as prostate, ovarian, colon, and metastatic melanoma ${ }^{[67-70]}$. BRK is a nonreceptor tyrosine kinase that is overexpressed in $60 \%$ of human breast tumors. Nevertheless, it is not expressed in normal human mammary gland and benign tumors ${ }^{[71,72]}$. A high BRK expression has been shown in invasive carcinoma, but it is also significantly expressed in HER2 and HER ${ }^{[73,74]}$. A previous study demonstrated that BRK contributes to upstream of p38 mitogen-activated protein (MAP) kinases and extracellular signal-regulated kinase 5 (ERK5) as well as downstream of epidermal growth factor receptor (ErbB) expression ${ }^{[75]}$. The overexpression and constitutive activation of BRK breast cancer cells subsequently induced elevated cell survival and anchorage-independent growth, respectively ${ }^{[76,77]}$. Similarly, constitutive BRK expression also induces the EGFR tyrosine kinase pathway and upregulates breast tumor cell migration via paxillin and Mitogen-activated protein kinase (MAPK) activation, and enhances cancer cell proliferation through phosphatidylinositol 3-kinase (PI3K) and Akt expression ${ }^{[13,76-78]}$.

Even though the exact cellular roles of BRK in breast cancer have yet to be fully delineated, recent data strongly imply that the deficiency of BRK in breast tumor cells can 
activate EGFR-regulated signaling molecules, preceding breast cancer cell proliferation, migration, and elevated MAPK activity ${ }^{[79,80]}$. Hence, further investigation on the BRK role in breast cancer is needed to achieve the optimum treatment outcome.

\subsection{Notch Signaling}

Notch signaling has been identified for more than two decades in developing the human mammary gland, governing a plethora of cellular activities such as stem cell maintenance, regulation of cell fate, differentiation, and proliferation, motility, and survival. Alterations of these processes are known to enhance human breast cancer progression ${ }^{[81]}$. While mammals have four Notch homologues, but solid tumors such as breast cancers may co-express some Notch homologues that grant them resistance to highly selective therapeutic agents. The oncogenic role of Notch has been shown in breast cancer tumorigenesis through cross-talk with some other signaling pathways, including estrogen, human epidermal growth factor receptor 2 (HER2), Ras, and Wnt signaling pathway ${ }^{[82]}$. For example, approximately $80 \%$ of breast malignancies treated with anti-estrogens develop treatment resistance, and it is believed to be due to the involvement of the Notch pathway ${ }^{[83]}$. Therefore, targeting in both signaling pathways concurrently may help to overcome or delay this undesired resistance.

Despite that, some Notch homologues may confer inhibitory action against cancer cells. As described by O' Neill et al. ${ }^{[84]}$, pro-oncogenic effects of Notch-1 and Notch-4 are counteracted by Notch-2 in human breast cancer cells. Notch-1 expression was found to be increased in poorly differentiated breast tumors, whereas expression of Notch-2 was increased in well-differentiated breast tumors. Additionally, a study suggested that Notch-1 may exert tumor-promoting properties while Notch-2 may possess tumor-suppressing functions ${ }^{[85]}$. The interactions between different Notch homologues could mean different cancer treatment outcomes, so taking a deeper look into these homologs' role could essentially assist the development of a promising treatment plan.

\subsection{Nuclear Factor-kappaB $(N F-\kappa B)$}

The nuclear factor-kappaB (NF- $\kappa \mathrm{B})$ superfamily comprises transcription factors that take on a crucial role in regulating processes such as angiogenesis, cell proliferation, cell invasion, cell migration, metastasis, and apoptosis ${ }^{[86-89]}$. In normal cells, the NF- $\kappa \mathrm{B}$ signalling pathway is tightly regulated. It can only be activated upon divergent stimulation of epidermal growth factor (EGF), bacteria and lipopolysaccharides (LPS), chemical and physical stresses, inflammatory cytokines such as interleukin (IL)- $1 \alpha$ and $\beta$ as well as tumor necrosis factor- $\alpha$

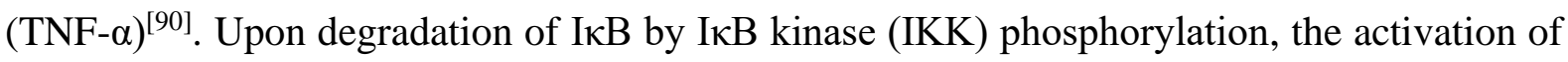
$\mathrm{NF}-\kappa \mathrm{B}$ signaling pathways commences with free p50 (NF- $\kappa \mathrm{B} 1)$ and $\mathrm{p} 65$ (RelA) subunit release into the cytoplasm before further activation of downstream pathways that lead to the physiological responses ${ }^{[91,92]}$.

Dysregulated activation of NF- $\kappa \mathrm{B}$ signaling pathways, which drives abnormal expression, has been observed in various types of human cancers ${ }^{[93,94]}$, including enhancing 
tumor's metastatic and angiogenic potential, increasing proliferation of cancer cells, and allowing cells to escape apoptotic processes ${ }^{[93,95]}$. In reality, various antiapoptotic factors comprise of the BCL2 family (such as Bcl-xL and Bcl-2), cellular inhibitors of apoptosis (cIAPs) and caspase-8/FADD (FAS-associated death domain)-like IL-1beta-converting enzyme (FLICE) inhibitory protein (c-FLIP) can be activated by NF- $\kappa$ B signaling pathways $^{[91,95]}$.

Increased NF- $\kappa \mathrm{B}$ activity can lead to abnormal chemokines expression and elevates cell migratory activity ${ }^{[92]}$. In line with that, several matrix metalloproteinases (MMPs) identified at $\kappa \mathrm{B}$ sites can enhance cell invasion of surrounding tissue ${ }^{[96]}$. Active NF- $\kappa \mathrm{B}$ also regulates the expression of specific molecules such as vascular cell adhesion molecule-1 (VCAM-1), intercellular adhesion molecule-1 (ICAM-1), and endothelial leukocyte adhesion molecule-1 (ELAM-1). These molecules are vital players in cancer metastasis, allowing vessel wall penetration to transport the cancer cells to distant parts of the body ${ }^{[86,95]}$. Likewise, high expression of $\mathrm{NF}-\mathrm{kB}$ protein stimulates extracellular matrix destruction by tumor cells, boosting the tumor's metastatic ability ${ }^{[97,98]}$. All in all, inhibiting aberrant activation of the NF$\kappa \mathrm{B}$ pathway illuminates potential therapeutic options in suppressing human cancer ${ }^{[99]}$.

\subsection{Human Epidermal Growth Factor Receptor (HER)}

Falling within the tyrosine kinase receptors family, the human epidermal growth factor receptor (HER) consists of four subfamilies and is usually expressed in normal tissues ${ }^{[100]}$. Amongst the subfamilies of HER, only human epidermal growth factor receptor 2 (HER2) is correlated to various breast cancers ${ }^{[101]}$. HER2 is found to be amplified in $20-30 \%$ of invasive breast tumors; its overexpression is associated with cancer cell proliferation, cancer development, and cancer cell metastasis, thus resulting in poor prognosis and a low survival rate in breast cancer patient ${ }^{[29,102]}$.

The FDA has approved therapeutic HER2-targeted drugs against metastatic breast cancer. These drugs include trastuzumab, lapatinib, and pertuzumab ${ }^{[103,104]}$. As reviewed by Vranic and the team recently, these anti-HER2 drugs can improve the outcome of patients with HER2-positive breast cancer when used alone or in combination with other conventional chemotherapeutics $^{[105]}$. However, trastuzumab resistance was reported to be developed in some patients, although a portion of them may show substantially improved outcomes ${ }^{[102]}$.

\section{Conclusions}

Breast cancer is the most common multifactorial disease occurred in women and brought the highest rate of death. A general model of breast cancer carcinogenesis postulates that a normal cell achieves several new capabilities, including genome instability, proliferate infinitely, resistance to cell-death signaling, angiogenesis, and escape from immune surveillance. These pathways may either work independently or inter-signaling to each other, contributing to multi-drug resistance (MDR), which is now a major challenge reported for breast cancer chemotherapy. A better understanding of breast cancer signaling pathways could 
help improve tumor treatment and prevent recurrence and metastasis. Therefore, therapeutic targeting in a specific signaling pathway would allow tailored treatments with more appropriate and effective individual responses, resulting in more personalized and conservative breast cancer interventions.

Author Contributions: The literature search and manuscript writing were performed by P-FC. The manuscript was proofread and edited by RAH. RAH conceptualized this project.

Funding: This research was funded by Ministry of Higher Education, Malaysia, grant number UM.C/HIRMOHE/SC/03 and UM.C/HIR-MOHE/SC/12.

Conflicts of Interest: The authors declare no conflict of interest.

\section{References}

1. Bray F, Ferlay J, Soerjomataram I, et al., Global cancer statistics 2018: GLOBOCAN estimates of incidence and mortality worldwide for 36 cancers in 185 countries. CA Cancer J Clin 2018; 68(6): 394424.

2. $\quad$ Stewart BW, and Wild, CW., World Cancer Report 2014. 2014, International Agency for Research on Cancer.

3. National Cancer Institute. Cancer Statistics. [Accessed 201830 November]; Available from: https://www.cancer.gov/about-cancer/understanding/statistics.

4. Tieng FYF, Abu N, Lee L-H, et al., Microsatellite instability in colorectal cancer liquid biopsy-Current Updates on Its potential in non-invasive detection, prognosis and as a predictive marker. Diagnostics 2021; 11(3): 544.

5. Ishak M, Baharudin R, Tan LT-H, et al., Landscape of HOXA genes methylation in colorectal cancer. Progress In Microbes \& Molecular Biology 2020; 3(1).

6. Law JW-F, Law LN-S, Letchumanan V, et al., anticancer drug discovery from microbial sources: The Unique mangrove Streptomycetes. Molecules 2020; 25(22): 5365.

7. Benson JR and Jatoi I, The global breast cancer burden. Future Oncol 2012; 8(6): 697-702.

8. Moore MA, Tajima K, Anh P, et al., Grand challenges in global health and the practical prevention program? Asian focus on cancer prevention in females of the developing world. Asian Pac J Cancer Prev 2003; 4(2): 153-165.

9. Sharma R, Global, regional, national burden of breast cancer in 185 countries: Evidence from GLOBOCAN 2018. Breast Cancer Res Treat 2021: 1-11.

10. Health Facts 2013. 2013, Ministry of Health Malaysia, Health Informatics Centre Planning Division.

11. Azizah AM, Saleha IT, Hashimah A, Asmah ZA, Mastulu W, Malaysia National Cancer Registry Report 2007-2011. Malaysia Cancer Statistics, Data and Figure. 2016, Ministry of Health.

12. Yang S-j, Wang D-d, Li J, et al., Predictive role of GSTP1-containing exosomes in chemotherapyresistant breast cancer. Gene 2017; 623: 5-14.

13. Chen H-Y, Shen C-H, Tsai Y-T, et al., Brk activates rac1 and promotes cell migration and invasion by phosphorylating paxillin. Mol Cell Biol 2004; 24(24): 10558-10572.

14. Sharma GN, Dave R, Sanadya J, et al., Various types and management of breast cancer: an overview. J Adv Pharm Technol Res 2010; 1(2): 109.

15. Yunos R-IM, Ab Mutalib N-S, Khor SS, et al., Whole exome sequencing identifies genomic alterations in proximal and distal colorectal cancer. Prog Microbe Mol Biol 2019; 2(1).

16. Stingl $\mathrm{J}$ and Caldas $\mathrm{C}$, Molecular heterogeneity of breast carcinomas and the cancer stem cell hypothesis. Nature Reviews. Cancer 2007; 7(10): 791-799. 
17. Connolly JL, Fechner RE, Kempson RL, et al., Recommendations for the reporting of breast carcinoma. Hum Pathol 1996; 27(3): 220-224.

18. Portschy PR, Marmor S, Nzara R, et al., Trends in incidence and management of lobular carcinoma in situ: a population-based analysis. Ann Surg Oncol 2013; 20(10): 3240-3246.

19. Malhotra GK, Zhao X, Band H, et al., Histological, molecular and functional subtypes of breast cancers. Cancer Biol Ther 2010; 10(10): 955-960.

20. Society AC. Understanding a breast cancer diagnosis. 2015 [Accessed 201522 December]; Available from: http://www.cancer.org/cancer/breastcancer/detailedguide/breast-cancer-breast-cancer-types.

21. Lester SC, Bose S, Chen Y-Y, et al., Protocol for the examination of specimens from patients with invasive carcinoma of the breast. Arch Pathol Lab Med 2009; 133(10): 1515-1538.

22. Pusztai L, Mazouni C, Anderson K, et al., Molecular classification of breast cancer: limitations and potential. Oncologist 2006; 11(8): 868-877.

23. Taherian-Fard A, Srihari S, and Ragan MA, Breast cancer classification: linking molecular mechanisms to disease prognosis. Brief Bioinform 2015; 16(3): 461-474.

24. Geyer FC, Marchiò C, and Reis-Filho JS, The role of molecular analysis in breast cancer. Pathology 2009; 41(1): 77-88.

25. Perou CM, Sørlie T, Eisen MB, et al., Molecular portraits of human breast tumours. Nature 2000; 406(6797): 747-752.

26. Sørlie T, Perou CM, Tibshirani R, et al., Gene expression patterns of breast carcinomas distinguish tumor subclasses with clinical implications. Proc Natl Acad Sci USA 2001; 98(19): 10869-10874.

27. Sørlie T, Tibshirani R, Parker J, et al., Repeated observation of breast tumor subtypes in independent gene expression data sets. Proc Natl Acad Sci USA 2003; 100(14): 8418-8423.

28. Andersen $\mathbf{J}$ and Poulsen HS, Immunohistochemical estrogen receptor determination in paraffinembedded tissue. Prediction of response to hormonal treatment in advanced breast cancer. Cancer 1989; 64(9): 1901-1908.

29. Slamon DJ, Godolphin W, Jones LA, et al., Studies of the HER-2/neu proto-oncogene in human breast and ovarian cancer. Science 1989; 244(4905): 707-712.

30. Stierer M, Rosen H, Weber R, et al., Immunohistochemical and biochemical measurement of estrogen and progesterone receptors in primary breast cancer. Correlation of histopathology and prognostic factors. Ann Surg 1993; 218(1): 13.

31. Nadji M, Gomez-Fernandez C, Ganjei-Azar P, et al., Immunohistochemistry of estrogen and progesterone receptors reconsidered: experience with 5,993 breast cancers. Am J Clin Pathol 2005; 123(1): 21-27.

32. Rouzier R, Perou CM, Symmans WF, et al., Breast cancer molecular subtypes respond differently to preoperative chemotherapy. Clin Cancer Res 2005; 11(16): 5678-5685.

33. Badve S, Dabbs DJ, Schnitt SJ, et al., Basal-like and triple-negative breast cancers: a critical review with an emphasis on the implications for pathologists and oncologists. Mod Pathol 2011; 24(2): 157-167.

34. Geyer FC, Rodrigues DN, Weigelt B, et al., Molecular classification of estrogen receptorpositive/luminal breast cancers. Adv Anat Pathol 2012; 19(1): 39-53.

35. Yersal O and Barutca S, Biological subtypes of breast cancer: Prognostic and therapeutic implications. World J Clin Oncol 2014; 5(3): 412.

36. Carey LA, Through a glass darkly: Advances in understanding breast cancer biology, 2000-2010. Clin Breast Cancer 2010; 10(3): 188-195.

37. Creighton CJ, The molecular profile of luminal B breast cancer. Biologics 2012; 6: 289. 
38. Kennecke H, Yerushalmi R, Woods R, et al., Metastatic behavior of breast cancer subtypes. J Clin Oncol 2010; 28(20): 3271-3277.

39. Guarneri V and Conte P, Metastatic breast cancer: therapeutic options according to molecular subtypes and prior adjuvant therapy. Oncologist 2009; 14(7): 645-656.

40. Ellis MJ, Tao Y, Luo J, et al., Outcome prediction for estrogen receptor-positive breast cancer based on postneoadjuvant endocrine therapy tumor characteristics. J Natl Cancer Inst 2008; 100(19): 1380-1388.

41. Reis-Filho JS, Weigelt B, Fumagalli D, et al., Molecular profiling: moving away from tumor philately. Sci Transl Med 2010; 2(47): 47ps43-47ps43.

42. Wirapati P, Sotiriou C, Kunkel S, et al., Meta-analysis of gene expression profiles in breast cancer: toward a unified understanding of breast cancer subtyping and prognosis signatures. Breast Cancer Res 2008; 10(4): 1-11.

43. Parker JS, Mullins M, Cheang MC, et al., Supervised risk predictor of breast cancer based on intrinsic subtypes. J Clin Oncol 2009; 27(8): 1160.

44. Gutierrez C and Schiff R, HER2: biology, detection, and clinical implications. Arch Pathol Lab Med 2011; 135(1): 55-62.

45. Tsang $\mathbf{J}$ and Tse GM, Molecular classification of breast cancer. Adv Anat Pathol 2020; 27(1): $27-35$.

46. Heitz F, Harter P, Lueck H-J, et al., Triple-negative and HER2-overexpressing breast cancers exhibit an elevated risk and an earlier occurrence of cerebral metastases. Eur J Cancer 2009; 45(16): 2792-2798.

47. Toft DJ and Cryns VL, Minireview: Basal-like breast cancer: from molecular profiles to targeted therapies. Mol Endocrinol 2011; 25(2): 199-211.

48. Perou CM, Molecular stratification of triple-negative breast cancers. Oncologist 2010; 15: 39-48.

49. Hallett RM, Dvorkin-Gheva A, Bane A, et al., A gene signature for predicting outcome in patients with basal-like breast cancer. Sci Rep 2012; 2(1): 1-8.

50. Kauraniemi P, Hautaniemi S, Autio R, et al., Effects of Herceptin treatment on global gene expression patterns in HER2-amplified and nonamplified breast cancer cell lines. Oncogene 2004; 23(4): 10101013.

51. Clemons M and Goss P, Estrogen and the risk of breast cancer. N Engl J Med 2001; 344(4): $276-285$.

52. Henderson BE, Ross RK, Pike MC, et al., Endogenous hormones as a major factor in human cancer. Cancer Res 1982; 42(8): 3232-3239.

53. Clamp A, Danson S, and Clemons M, Hormonal and genetic risk factors for breast cancer. Surgeon 2003; 1(1): $23-31$.

54. Tinelli A, Malvasi A, Leo G, et al., Hereditary ovarian cancers: from BRCA mutations to clinical management. A modern appraisal. Cancer Metastasis Rev 2010; 29(2): 339-350.

55. Downs B and Wang SM, Epigenetic changes in BRCA1-mutated familial breast cancer. Cancer Genet 2015; 208(5): 237-240.

56. van Verschuer VM, Hooning MJ, van Baare-Georgieva RD, et al., Tumor-associated inflammation as a potential prognostic tool in BRCA1/2-associated breast cancer. Hum Pathol 2015; 46(2): 182-190.

57. Mincey BA, Genetics and the management of women at high risk for breast cancer. Oncologist 2003; 8(5): 466-473.

58. Brédart A, Kop J-L, De Pauw A, et al., Effect on perceived control and psychological distress of genetic knowledge in women with breast cancer receiving a BRCA1/2 test result. Breast 2017; 31: 121-127.

59. Martin A-M and Weber BL, Genetic and hormonal risk factors in breast cancer. J Natl Cancer Inst 2000; 92(14): 1126-1135. 
60. Pisanò M, Mezzolla V, Galante MM, et al., A new mutation of BRCA2 gene in an Italian healthy woman with familial breast cancer history. Fam Cancer 2011; 10(1): 65-71.

61. Kamdje AHN, Etet PFS, Vecchio L, et al., New targeted therapies for breast cancer: A focus on tumor microenvironmental signals and chemoresistant breast cancers. World J Clin Cases 2014; 2(12): 769.

62. Place AE, Huh SJ, and Polyak K, The microenvironment in breast cancer progression: biology and implications for treatment. Breast Cancer Res 2011; 13(6): 1-11.

63. Nurse P, Cyclin dependent kinases and cell cycle control (nobel lecture). ChemBioChem 2002; 3(7): 596-603.

64. Finn RS, Aleshin A, and Slamon DJ, Targeting the cyclin-dependent kinases (CDK) 4/6 in estrogen receptor-positive breast cancers. Breast Cancer Res 2016; 18(1): 1-11.

65. Landis MW, Pawlyk BS, Li T, et al., Cyclin D1-dependent kinase activity in murine development and mammary tumorigenesis. Cancer Cell 2006; 9(1): 13-22.

66. Yu Q, Sicinska E, Geng Y, et al., Requirement for CDK4 kinase function in breast cancer. Cancer Cell 2006; 9(1): 23-32.

67. Easty DJ, Mitchell PJ, Patel K, et al., Loss of expression of receptor tyrosine kinase family genes PTK7 and SEK in metastatic melanoma. Int J Cancer 1997; 71(6): 1061-1065.

68. Llor X, Serfas MS, Bie W, et al., BRK/Sik expression in the gastrointestinal tract and in colon tumors. Clin Cancer Res 1999; 5(7): 1767-1777.

69. Derry JJ, Prins GS, Ray V, et al., Altered localization and activity of the intracellular tyrosine kinase BRK/Sik in prostate tumor cells. Oncogene 2003; 22(27): 4212-4220.

70. Schmandt RE, Bennett M, Clifford S, et al., The BRK tyrosine kinase is expressed in high-grade serous carcinoma of the ovary. Cancer Biol Ther 2006; 5(9): 1136-1141.

71. Mitchell PJ, Barker KT, Martindale JE, et al., Cloning and characterisation of cDNAs encoding a novel non-receptor tyrosine kinase, brk, expressed in human breast tumours. Oncogene 1994; 9(8): 2383-2390.

72. Aubele M, Vidojkovic S, Braselmann H, et al., Overexpression of PTK6 (breast tumor kinase) proteina prognostic factor for long-term breast cancer survival-is not due to gene amplification. Virchows Arch 2009; 455(2): 117-123.

73. Born M, Quintanilla-Fend L, Braselmann H, et al., Simultaneous over-expression of the Her2/neu and PTK6 tyrosine kinases in archival invasive ductal breast carcinomas. J Pathol 2005; 205(5): 592-596.

74. Ostrander JH, Daniel AR, and Lange CA, Brk/PTK6 signaling in normal and cancer cell models. Curr Opin Pharmacol 2010; 10(6): 662-669.

75. Castro NE and Lange CA, Breast tumor kinase and extracellular signal-regulated kinase 5 mediate Met receptor signaling to cell migration in breast cancer cells. Breast Cancer Res 2010; 12(4): 1-15.

76. Kamalati T, Jolin HE, Mitchell PJ, et al., Brk, a breast tumor-derived non-receptor protein-tyrosine kinase, sensitizes mammary epithelial cells to epidermal growth factor. J Biol Chem 1996; 271(48): 30956-30963.

77. Harvey AJ, Pennington CJ, Porter S, et al., Brk protects breast cancer cells from autophagic cell death induced by loss of anchorage. Am J Pathol 2009; 175(3): 1226-1234.

78. Ikeda O, Miyasaka Y, Sekine Y, et al., STAP-2 is phosphorylated at tyrosine-250 by Brk and modulates Brk-mediated STAT3 activation. Biochem Biophys Res Commun 2009; 384(1): 71-75.

79. Ludyga N, Anastasov N, Gonzalez-Vasconcellos I, et al., Impact of protein tyrosine kinase 6 (PTK6) on human epidermal growth factor receptor (HER) signalling in breast cancer. Mol Biosyst 2011; 7(5): 1603-1612. 
80. Miah S, Martin A, and Lukong K, Constitutive activation of breast tumor kinase accelerates cell migration and tumor growth in vivo. Oncogenesis 2012; 1(5): e11-e11.

81. Reedijk M, Notch signaling and breast cancer. Notch Signaling Embryol Cancer 2012: 241-257.

82. Al-Hussaini H, Subramanyam D, Reedijk M, et al., Notch signaling pathway as a therapeutic target in breast cancer. Mol Cancer Ther 2011; 10(1): 9-15.

83. Rizzo P, Osipo C, Foreman K, et al., Rational targeting of Notch signaling in cancer. Oncogene 2008; 27(38): 5124-5131.

84. O'Neill CF, Urs S, Cinelli C, et al., Notch2 signaling induces apoptosis and inhibits human MDA-MB231 xenograft growth. Am J Pathol 2007; 171(3): 1023-1036.

85. Parr C, Watkins G, and Jiang W, The possible correlation of Notch-1 and Notch-2 with clinical outcome and tumour clinicopathological parameters in human breast cancer. Int J Mol Med 2004; 14(5): 779-786.

86. Sethi G, Sung B, and Aggarwal B, Nuclear factor-kappaB activation: from bench to bedside (2008) Exp Biol Med (Maywood) 233: 21-31.

87. Smith SM, Lyu YL, and Cai L, NF- $\kappa$ B affects proliferation and invasiveness of breast cancer cells by regulating CD44 expression. PLoS One 2014; 9(9): e106966.

88. Adhikary A, Mohanty S, Lahiry L, et al., Theaflavins retard human breast cancer cell migration by inhibiting NF- $\kappa$ B via p53-ROS cross-talk. FEBS Lett 2010; 584(1): 7-14.

89. Parajuli B, Lee H-G, Kwon S-H, et al., Salinomycin inhibits Akt/NF- $\kappa$ B and induces apoptosis in cisplatin resistant ovarian cancer cells. Cancer Epidemiol 2013; 37(4): 512-517.

90. Aggarwal S, Ichikawa H, Takada Y, et al., Curcumin (diferuloylmethane) down-regulates expression of cell proliferation and antiapoptotic and metastatic gene products through suppression of I $\mathrm{B} \alpha$ kinase and Akt activation. Mol Pharmacol 2006; 69(1): 195-206.

91. Karin M and Delhase M. The I $\mathrm{MB}$ kinase (IKK) and $N F-\kappa B$ : key elements of proinflammatory signalling. in Semin Immunol. 2000. Elsevier.

92. Karin M, Cao Y, Greten FR, et al., NF- $\mathrm{BB}$ in cancer: From innocent bystander to major culprit. Nature reviews. Cancer 2002; 2(4): 301-310.

93. Prasad S, Ravindran J, and Aggarwal BB, NF- $\mathrm{KB}$ and cancer: How intimate is this relationship. Mol Cell Biochem 2010; 336(1): 25-37.

94. Sovak MA, Bellas RE, Kim DW, et al., Aberrant nuclear factor-kappaB/Rel expression and the pathogenesis of breast cancer. J Clin Invest 1997; 100(12): 2952-2960.

95. Ukaji T and Umezawa K, Novel approaches to target NF- $\mathrm{BB}$ and other signaling pathways in cancer stem cells. Adv Biol Regul 2014; 56: 108-115.

96. Overall CM and López-Otín C, Strategies for MMP inhibition in cancer: innovations for the post-trial era. Nature Reviews. Cancer 2002; 2(9): 657-672.

97. Bartok B and Firestein GS, Fibroblast-like synoviocytes: key effector cells in rheumatoid arthritis. Immunol Rev 2010; 233(1): 233-255.

98. Pickup MW, Mouw JK, and Weaver VM, The extracellular matrix modulates the hallmarks of cancer. EMBO 2014; 15(12): 1243-1253.

99. Park $\mathrm{MH}$ and Hong JT, Roles of NF- $\mathrm{BB}$ in cancer and inflammatory diseases and their therapeutic approaches. Cells 2016; 5(2): 15.

100. Zhang H, Berezov A, Wang Q, et al., ErbB receptors: from oncogenes to targeted cancer therapies. J Clin Invest 2007; 117(8): 2051-2058.

101. King CR, Kraus MH, and Aaronson SA, Amplification of a novel v-erbB-related gene in a human mammary carcinoma. Science 1985; 229(4717): 974-976. 
102. Dedić Plavetić N, Kulić A, and Vrbanec D, Role of HER2 signaling pathway in breast cancer: Biology, detection and therapeutical implications. Period Biol 2012; 114(4): 505-510.

103. Orphanos $\mathrm{G}$ and Kountourakis $\mathrm{P}$, Targeting the HER2 receptor in metastatic breast cancer. Hematol Oncol Stem Cell Ther 2012; 5(3): 127-137.

104. Nielsen DL, Kümler I, Palshof JA, et al., Efficacy of HER2-targeted therapy in metastatic breast cancer. Monoclonal antibodies and tyrosine kinase inhibitors. Breast 2013; 22(1): 1-12.

105. Vranić S, Bešlija S, and Gatalica Z, Targeting HER2 expression in cancer: New drugs and new indications. Bosn J Basic Med Sci 2021; 21(1): 1.

Author(s) shall retain the copyright of their work and grant the Journal/Publisher right for the first publication with the work simultaneously licensed under:

Creative Commons Attribution-NonCommercial 4.0 International (CC BY-NC 4.0). This license allows for the copying, distribution and transmission of the work, provided the correct attribution of the original creator is stated. Adaptation and remixing are also permitted. 